\title{
Case Report: An unusual case of small bowel volvulus
}

\section{associated with pneumatosis intestinalis [version 1; peer}

\section{review: 3 approved with reservations]}

\author{
Alia Zouaghi (D1), Dhafer Hadded (D1), Mesbahi Meryam (D1, Yazid Benzarti1, \\ Mona Cherif1, Haithem Zaafouri (D1), Khalil Ben Massoud (D)2, Chiraz Chamekhi(iD2, \\ Anis Ben Maamer ${ }^{1}$ \\ ${ }^{1}$ Department of General Surgery, Habib thameur Hospital, Tunis, Tunis, 1000, Tunisia \\ ${ }^{2}$ Department of Radiology, Habib Thameur Hospital, Tunis, Tunis, 1000, Tunisia
}

\begin{tabular}{l}
\hline V1 First published: 21 Sep 2021, 10:951 \\
https://doi.org/10.12688/f1000research.73042.1 \\
Latest published: 24 Nov 2022, 10:951 \\
https://doi.org/10.12688/f1000research.73042.2 \\
\hline
\end{tabular}

\section{Abstract}

Pneumatosis cystoid intestinalis is a rare disease reported in the literature affecting $0.03 \%$ of the population. It has a variety of causes and its manifestation may change widely. It usually presents as a marginal finding resulting from various gastrointestinal pathologies. In the acute complicated form of pneumatosis intestinalis, management is challenging for physicians and surgeons.

We present a case of a 60-year-old patient who was admitted to our surgical department with a symptomatology suggestive of small bowel occlusion. Computed tomography demonstrated ileal volvulus associated with parietal signs suffering and pneumoperitoneum. An emergent exploratory laparoscopy followed by conversion was performed demonstrating segmental ileal pneumatosis intestinalis secondary to a small bowel volvulus due to an inflammatory appendix wrapping around the distal ileum. Further, detorsion, retrograde draining, and appendectomy were performed because there were no signs of necrosis and the appendix was pathological. The postoperative course was uneventful.

This case is exceedingly rare in the literature, because it was featured by the ileal volvulus due to appendicitis. This case report emphasizes the importance of surgical procedures in the management of symptomatic pneumatosis intestinalis.

\section{Keywords}

Pneumatosis cystoid intestinalis, small bowel volvulus, acute abdomen, case report

\section{Open Peer Review}

Approval Status? ? ?

12 3

version 2

(revision)

24 Nov 2022

$\begin{array}{cccc}\text { version } 1 & ? & ? & ? \\ 21 \text { Sep 2021 } & \text { view } & \text { view } & \text { view }\end{array}$

1. Gennaro Martines ID, University "Aldo Moro" of Bari, Bari, Italy

2. Jaques Waisberg (iD) Institute of Medical Assistance to State Civil Servants (IAMSPE), Sao Paulo, Brazil

3. Cristian Mesina, Craiova University of Medicine and Pharmacy, Craiova, Romania Any reports and responses or comments on the article can be found at the end of the article. 
Corresponding author: Mesbahi Meryam (Meryam.mesbahi@gmail.com)

Author roles: Zouaghi A: Investigation; Hadded D: Methodology; Meryam M: Writing - Review \& Editing; Benzarti Y: Writing - Original Draft Preparation; Cherif M: Visualization; Zaafouri H: Methodology; Ben Massoud K: Investigation; Chamekhi C: Validation; Ben

Maamer A: Validation

Competing interests: No competing interests were disclosed.

Grant information: The author(s) declared that no grants were involved in supporting this work.

Copyright: $\odot 2021$ Zouaghi A et al. This is an open access article distributed under the terms of the Creative Commons Attribution License, which permits unrestricted use, distribution, and reproduction in any medium, provided the original work is properly cited.

How to cite this article: Zouaghi A, Hadded D, Meryam M et al. Case Report: An unusual case of small bowel volvulus associated with pneumatosis intestinalis [version 1; peer review: 3 approved with reservations] F1000Research 2021, 10:951

https://doi.org/10.12688/f1000research.73042.1

First published: 21 Sep 2021, 10:951 https://doi.org/10.12688/f1000research.73042.1 


\section{Introduction}

Pneumatosis cystoid intestinalis (PCI) is a low-incidence pathology defined by the existence of air in the small intestine or colon wall. ${ }^{1}$ PCI can affect any portion of the gastrointestinal tract and could be present in any layer such as the mucosa, submucosa, or subserosa. ${ }^{1-3}$ It can either be presented as a secondary form in $85 \%$ of cases or an idiopathic form in $15 \%$ of cases. ${ }^{1,2}$ The secondary pattern occurs more frequently in gastrointestinal causes such as bowel obstruction. ${ }^{3,4}$ The management of PCI is challenging to surgeons especially in symptomatic cases. ${ }^{5}$ We report a rare case of ileal pneumatosis cystoides associated with small bowel volvulus, presenting with acute abdominal pain. This case is exceedingly rare in the literature, because it was featured by the ileal volvulus due to appendicitis.

\section{Case report}

A 60-year-old retired, north African male patient without any medical or surgical history consulted the emergency department for 24 hours of abdominal pain, distension, and vomiting. The patient had experienced this pain a year earlier, but did not consult any doctor, and the pain faded away spontaneously. On physical examination, tachycardia and distended abdomen with mild tenderness were noted. White blood count was $8840 \mathrm{E} / \mathrm{mm}^{3}$ and C reactive protein was $36 \mathrm{mg} / \mathrm{l}$ (normal values: White blood count: $4000 \mathrm{E} / \mathrm{mm}^{3}$, and C reactive protein: $1 \mathrm{mg} / \mathrm{l}$ ). X-ray of thorax and abdomen showed dilated small bowel, multiple fluid levels and pneumoperitoneum (Figure 1).

An abdominal CT scan was performed, revealing distended small bowel loops upstreaming transitional levels like a 'whirl sign' (Figure 2), a bubbly pattern across the length of the small bowel associated with parietal suffering signs (Figure 3), abundant pneumoperitoneum (Figure 4), and a pathological meso-celiac appendix (Figure 5). The CT scan suggested a diagnosis of ileal volvulus due to the meso-celiac appendix.

We initially decided to perform laparoscopy. Intraoperatively, small bowel loops were much dilated not allowing intraperitoneal exploration. Gas-filled cystic lesions on small bowel serosa were identified. There was no evidence of perforation. We did choose to convert into midline incision for better and prudent exploration. A volvulus was found, involving a two-and-a-half clockwise turn around a long, pendulous small bowel mesentery, the strangled bowel was

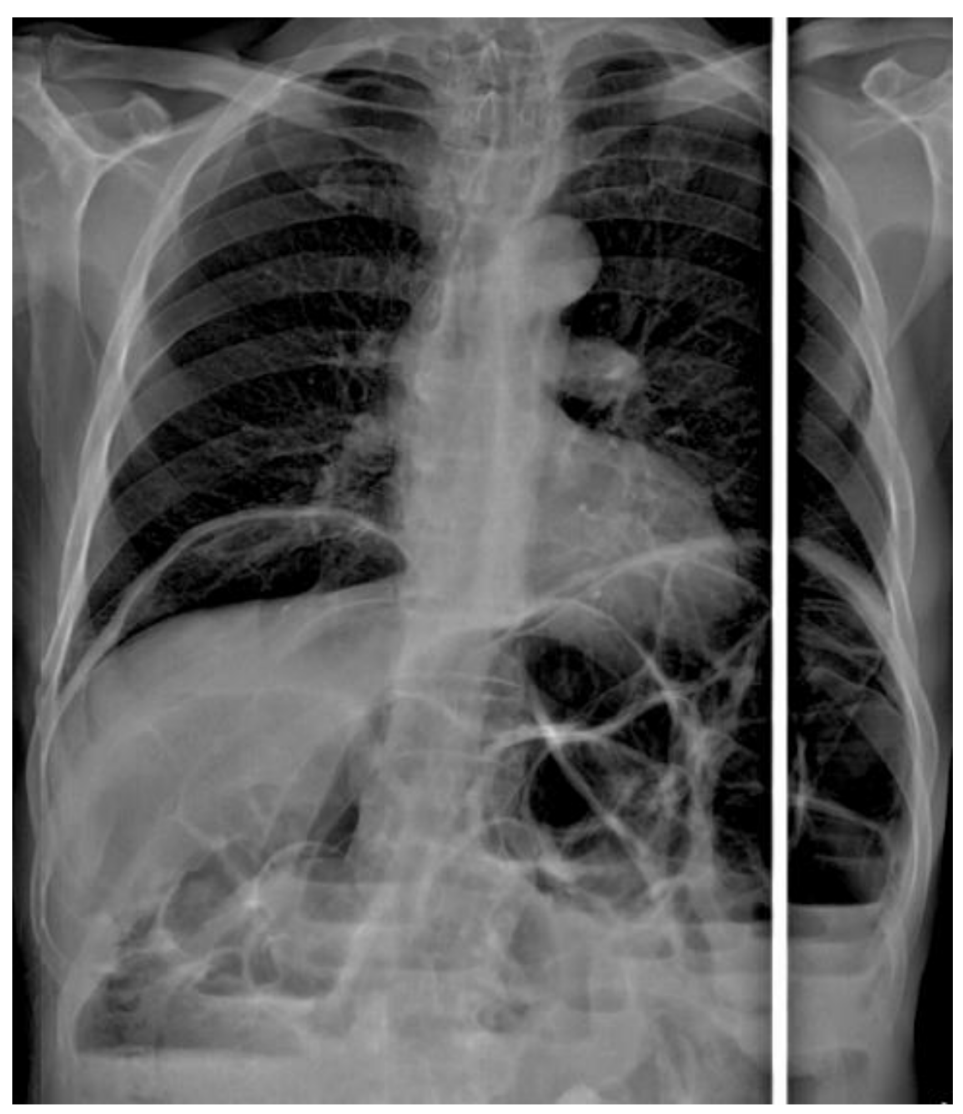

Figure 1. Dilated small bowel, multiple fluid levels and pneumoperitoneum on X-ray. 


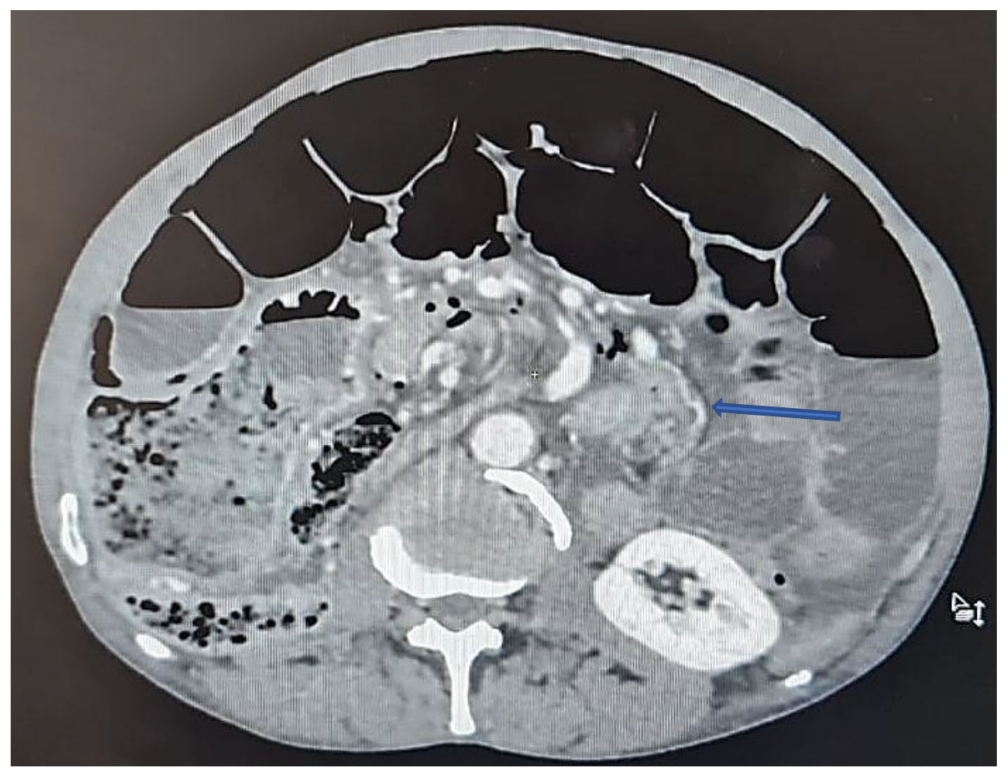

Figure 2. Ileal volvulus: dilated bowel segments associated with whirl sign.

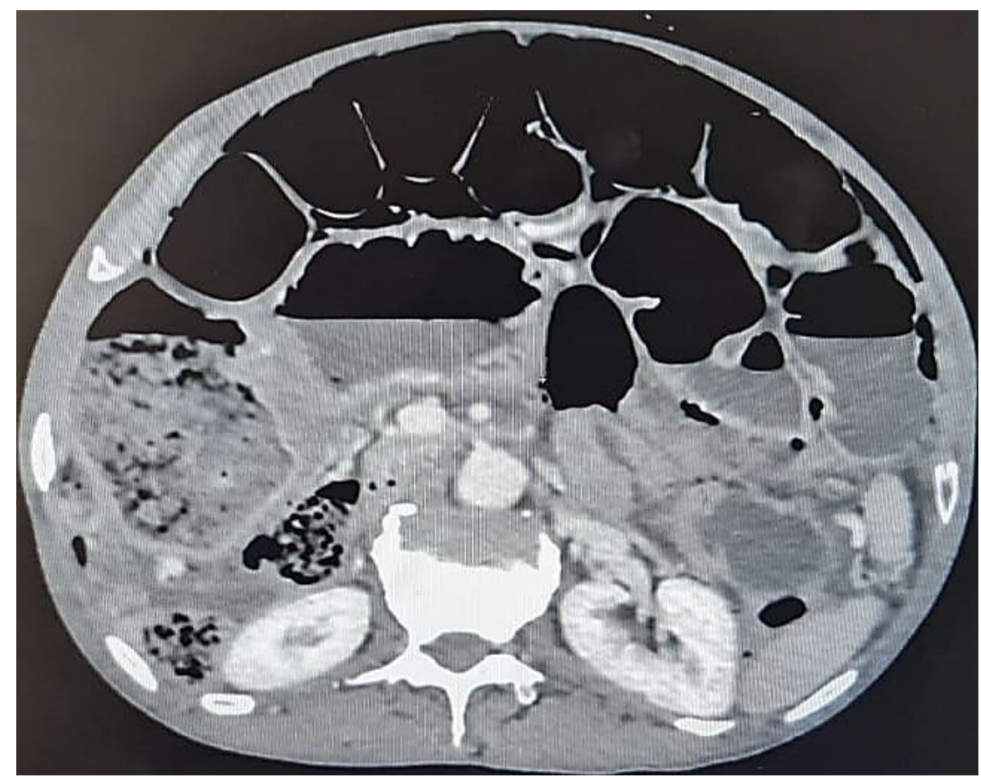

Figure 3. Multiple bubble lesions among ileal loops on Abdominal CT.

greatly congested (Figure 6). At the base of the volvulus, an inflammatory appendix was wrapped around the last loop of the ileum (Figure 7). Also, multiple gas-filled subserosal cysts, differently sized, on the wall of the ileum were encountered (Figure 8). When the ileum was re-rotated, small bowel loops had preserved vitality. The entire colon was normal. Detorsion, retrograde draining, and appendectomy were performed because there were no signs of necrosis and the appendix was pathological.

Postoperatively, the patient completed a five-day course of intravenous metronidazole $500 \mathrm{mg}$ three times a day. There were no postoperative complications. Anatomopathological examination revealed an inflammatory appendix without malignancy. A lower endoscopy was completed after surgery. It showed the presence of two polyps on the rectum and the transverse colon in low-grade dysplasia with no other lesions that were resected. There was no malignancy on the anatomopathological examination. The patient was monitored regularly, and the long-term post-operative course was uneventful. 


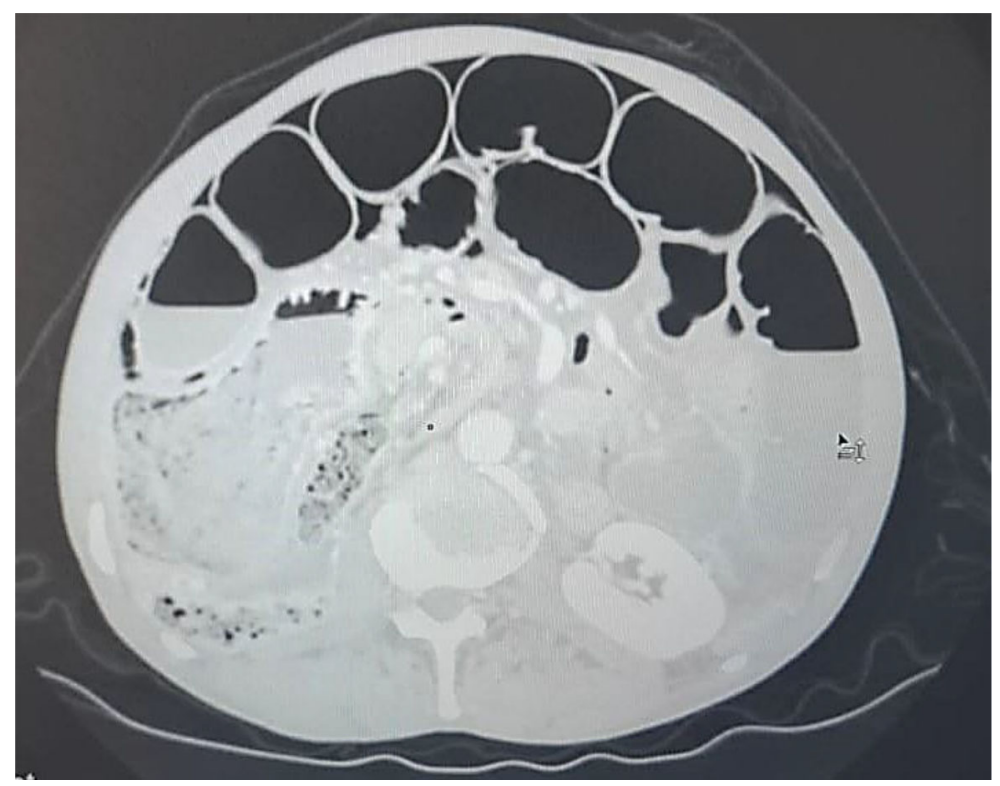

Figure 4. Abundant pneumoperitoneum.

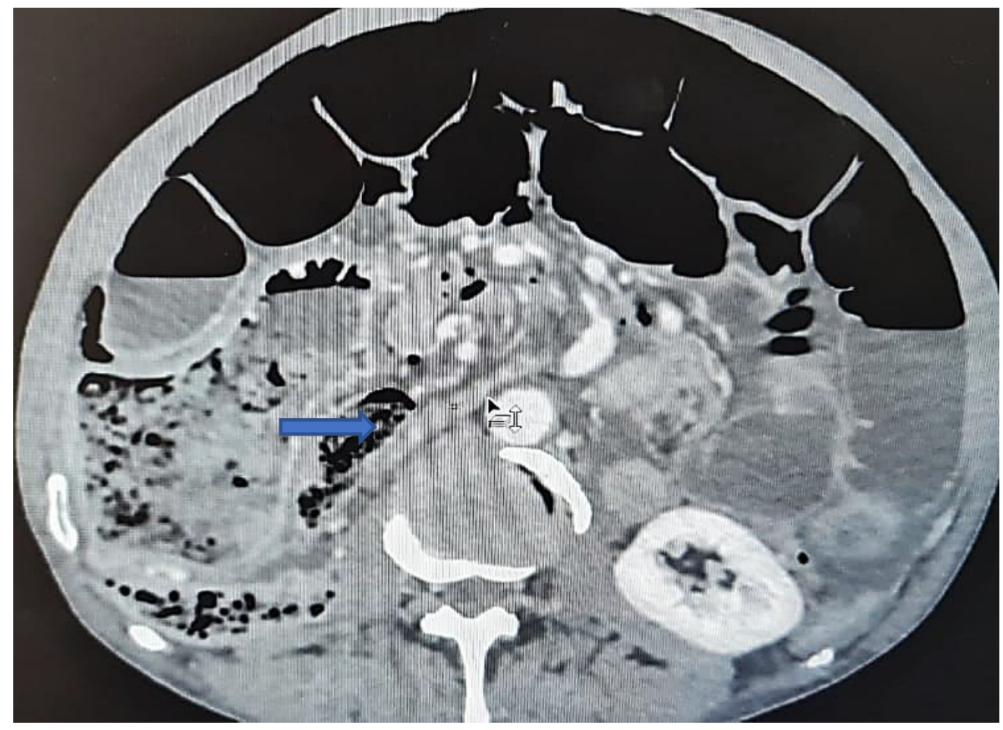

Figure 5. The inflammatory appendix.

\section{Discussion}

PCI is an uncommon disease $(0.03 \% \text { of adults })^{6}$ and its pathogenesis is still not clear. ${ }^{7}$ According to its etiology, literature classifies this entity mainly as primary or secondary type. ${ }^{8}$ There is also an idiopathic type which usually affects the left colon and is rarely reported in the literature. We found that thirteen cases of primary PCI have been described in the international literature (Table 1). The secondary type frequently affects the small intestine and the right colon. ${ }^{9}$ Its pathogenesis is multifactorial and can be explained by 3 theories: mucosal disruption, bacterial theory, and pulmonary disease. ${ }^{1,7,10,11}$ The mucosal disruption is due to the dissemination of bowel gas through a mucosal defect into lymphatic channels. ${ }^{1,10} \mathrm{Wu}$ et al. ${ }^{12}$ found that high altitude is a new theory explaining PCI's pathogenesis. Highland areas induce passage of intraluminal gas into the submucosa damaging the mucosa. Mucosal damage can result from bowel occlusion, inflammatory process, and cytotoxic medical treatment. ${ }^{11}$ The pulmonary cause is confirmed in patients with asthma and chronic bronchitis. In these cases, the rupture of alveoli causes the migration of air bubbles from interstitial spaces through the mediastinum and from the retroperitoneum to the blood vessel of the intestinal wall. ${ }^{1,8,10}$ However, the bacterial theory is explained by entry of bacterial gas due to a defect on the bowel wall lymphoid tissue. ${ }^{8,10}$ This mechanism can 


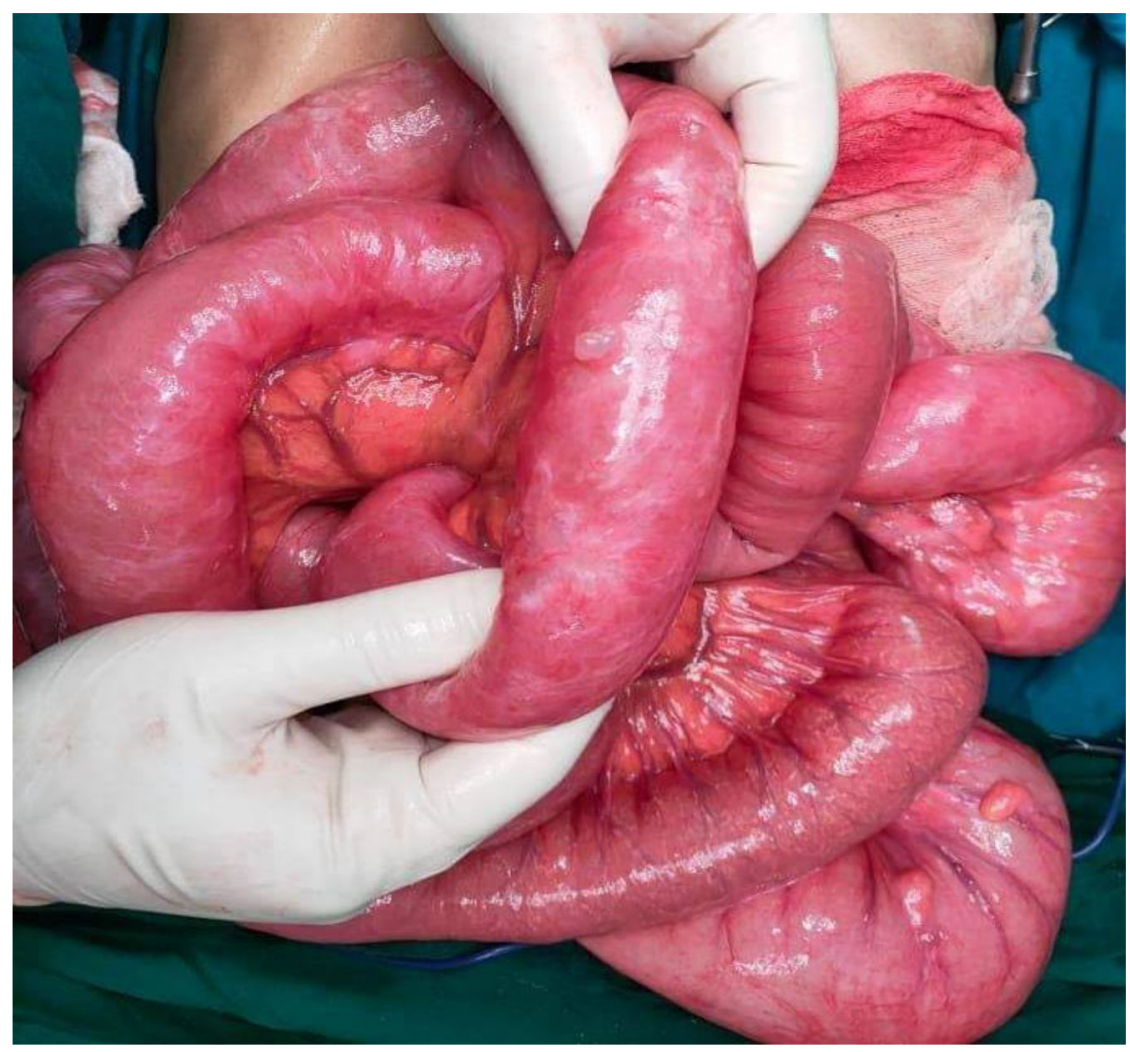

Figure 6. Ileal loop volvulus, involving a two-and-a-half clockwise turn around a long, pendulous small bowel mesentery.

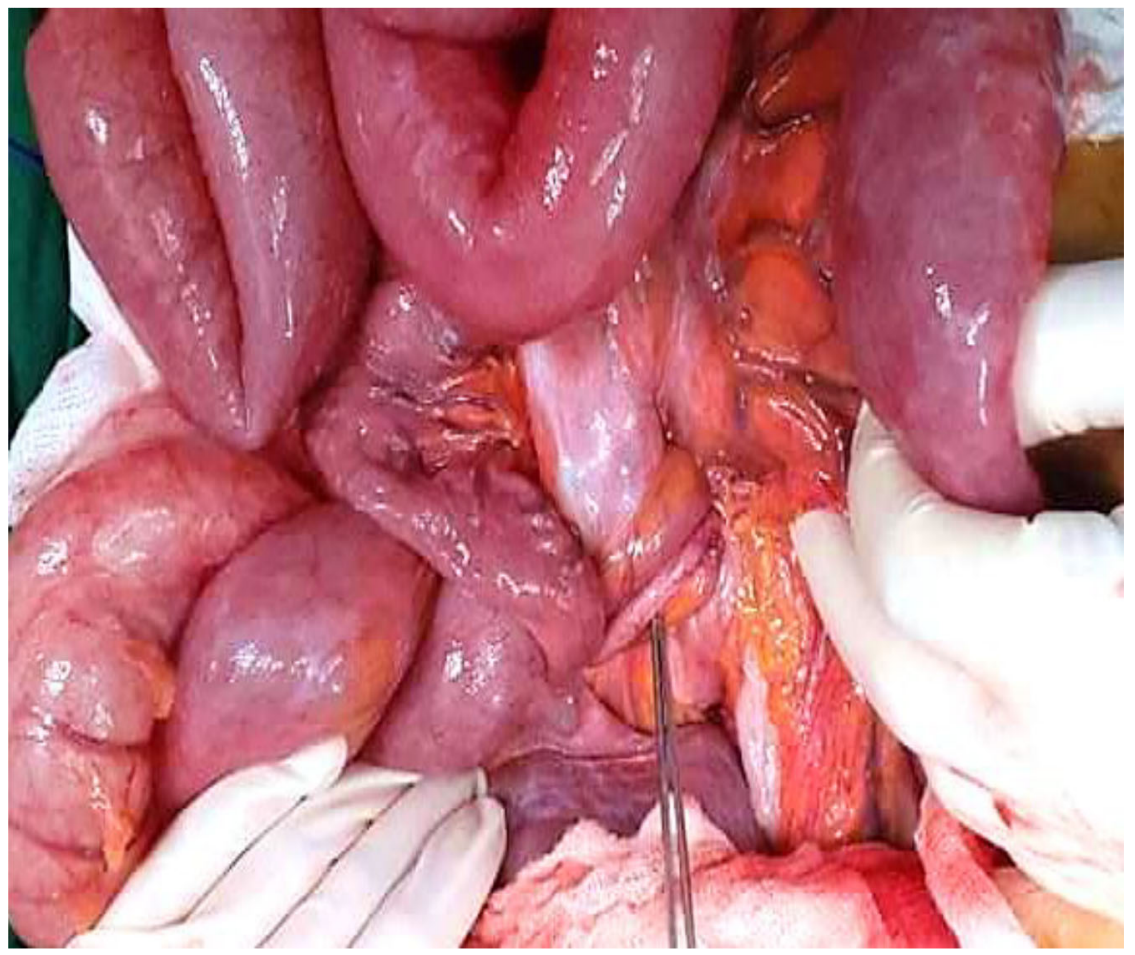

Figure 7. At the base of the volvulus, the inflammatory appendix wrapped around the last loop of the ileum. 


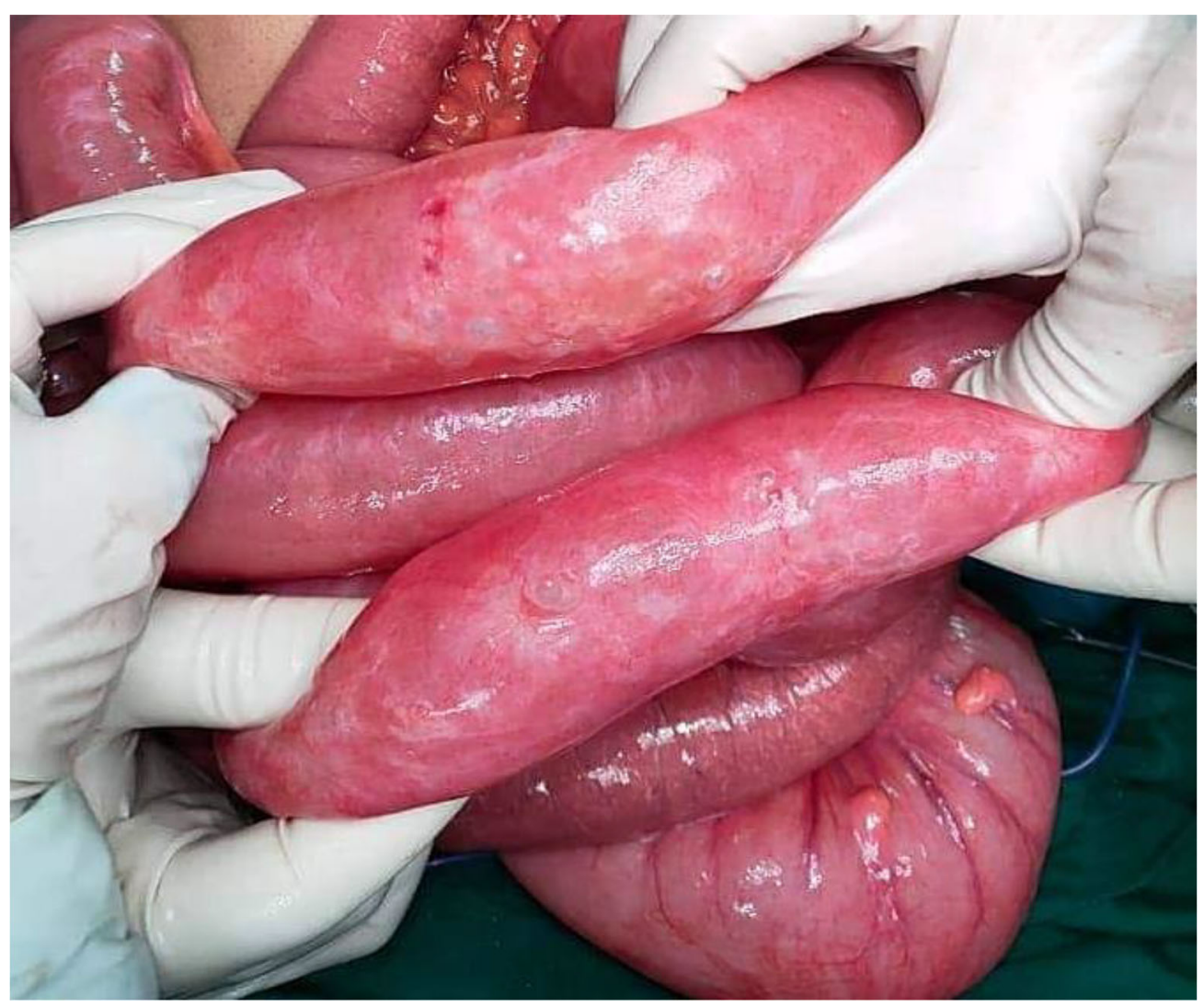

Figure 8. Segmental pneumatosis intestinalis involving the ileal loops.

justify the use of antibiotics. ${ }^{1}$ Chemotherapy or hormonal therapy, and systemic sclerosis were also reported in the literature as a cause of PCI. ${ }^{1}$ Finally, while keeping in mind these theories, their pathogenesis has not been yet fully clarified. ${ }^{1}$

Besides, the disease's location on the digestif tractus may be helpful to guide the etiology. So pyloric stenosis or gastric cancer can lead to a proximal pathology; however distant one might be due to mesenteric ischemia or diverticulitis. ${ }^{9}$

PCI is a rare entity reported in the literature, but nowadays PCI reports' number has been increasing because of the widespread use of CT scan and colonoscopy. ${ }^{9}$ This pathology is more frequently asymptomatic. ${ }^{1}$ Whereas in some cases, they may present with symptoms such as abdominal pain, constipation, distension, diarrhea, or bleeding. ${ }^{8,9}$ Incidentally PCI can induce surgical complications such as bowel obstruction, intestinal perforation, volvulus, intussusception, and bleeding, which require surgical intervention. ${ }^{13}$

Intestinal obstruction can be a rare complication of PCI. This event depends on the size and number of the cysts which lead in certain cases to a reduction of the intestinal lumen, volvulus, perforation, and hemorrhage. ${ }^{7,11}$ In the literature, PCI associated with volvulus is much more uncommon. Besides this association, one of the highlights of our case is the long and hypermobile small bowel mesentery. Moreover, PCI is discussed to be a mechanical factor leading to irreversible volvulus, also it is disputed that volvulus contributes to ischemia which is an etiological factor leading to PCI. ${ }^{3,14}$

Imaging findings may be helpful to confirm PCI diagnosis, especially on CT scans. ${ }^{1,6}$ Computed tomography can show a grape cluster aspect within the wall of the intestine. ${ }^{1}$ Three patterns of pneumatosis have been reported in the literature using CT scan imaging: bubble cystoid, a linear pattern, and a circular pattern. ${ }^{1}$

Pneumoperitoneum can be explained by the rupture of the cyst on the wall intestine, without any evidence of peritoneal irritation or digestive perforation, like in our case. So that we should be wise to correlate clinical and radiographic findings, when free air is present below the diaphragm in chest X-ray. ${ }^{8,9}$ Pneumatosis intestinalis and portomesenteric venous gas (PVG) are generally debated independently in the literature. This association of radiological findings usually 


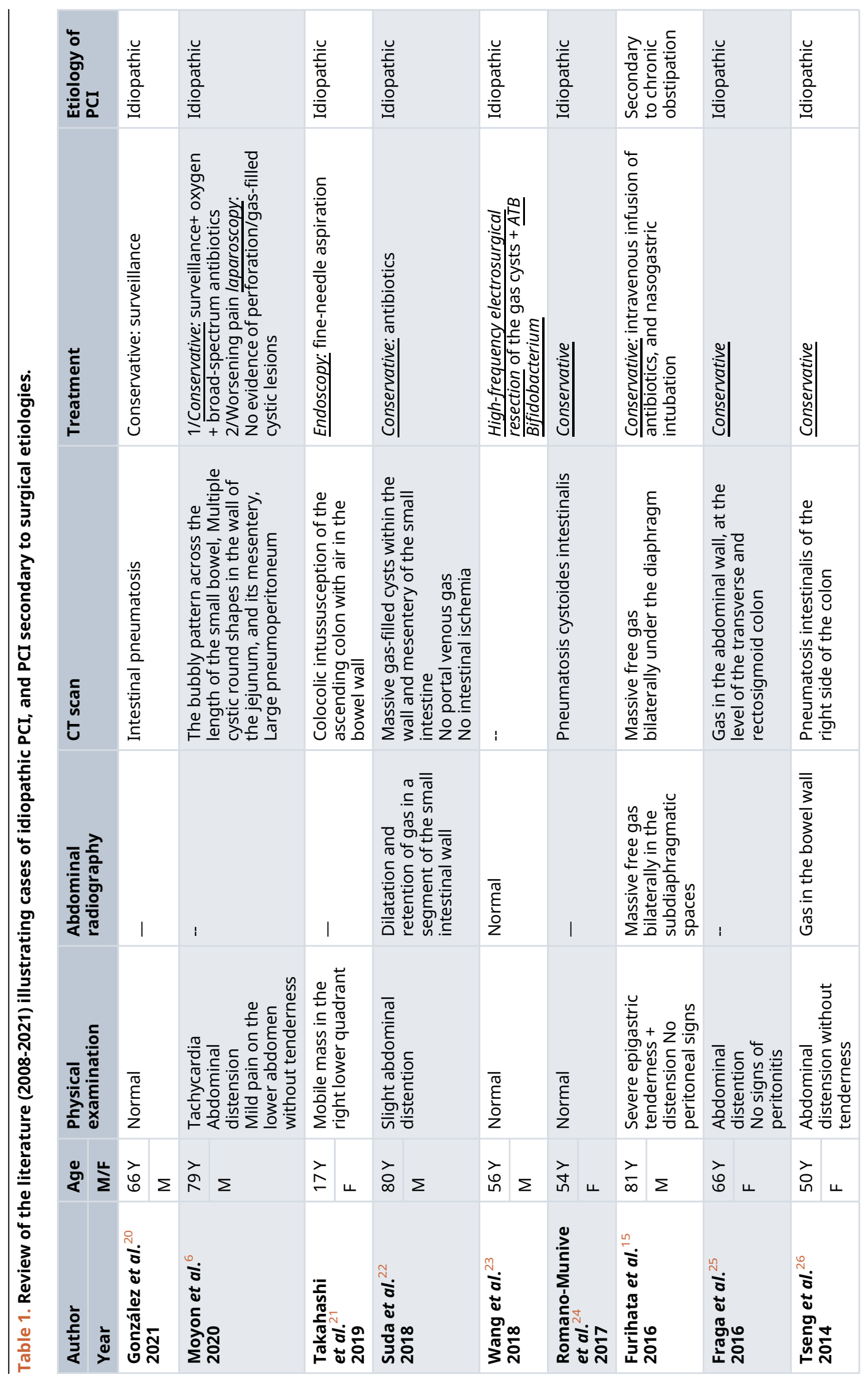




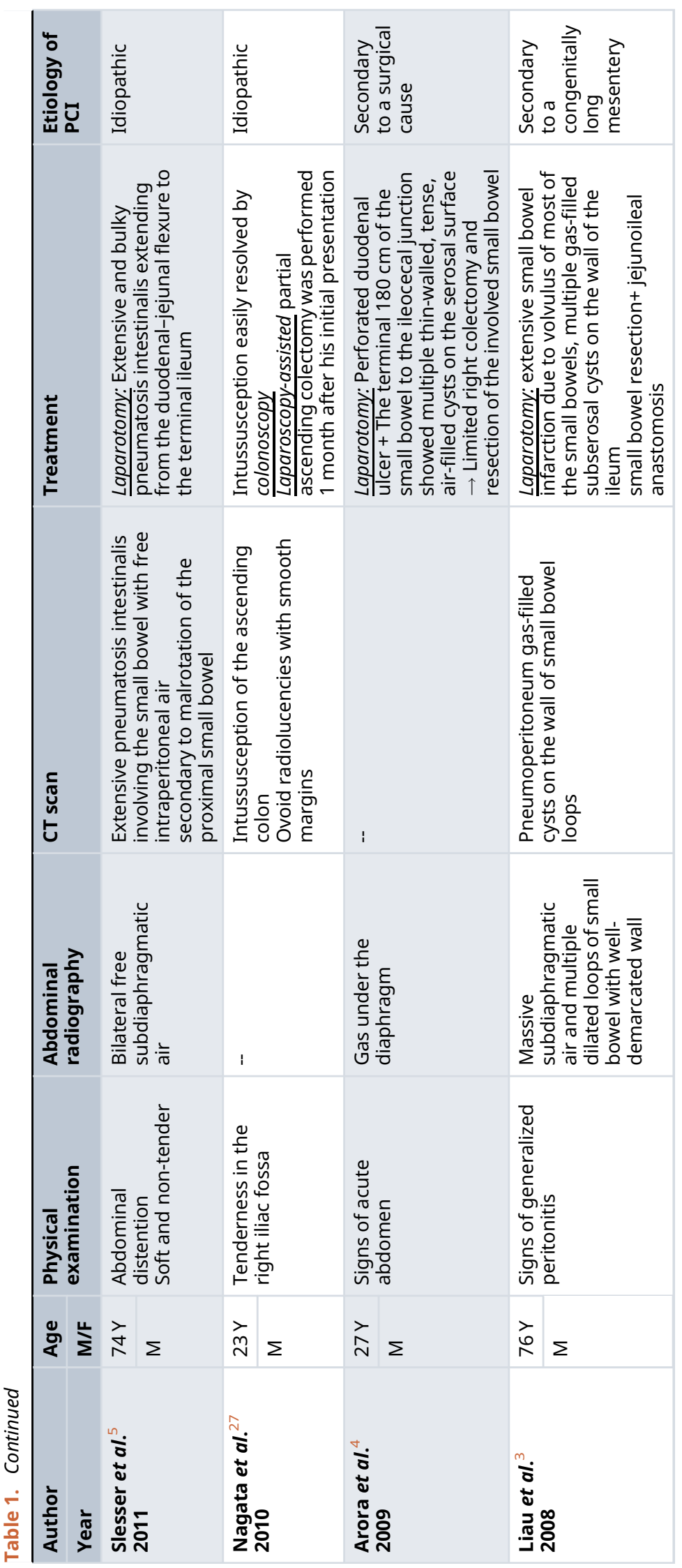


concludes to the presence of mesenteric infarction, but they may indicate occasionally nonischemic conditions. So that their presence should not be always regarded as signs of severity. ${ }^{13,15,16}$ Moreover, according to literature, the rare findings of PCI and PVG can be present in asymptomatic patients without ominous signs, as described in the series of Sooby et al. ${ }^{17}$ including 88 patients with PCI/PVG of which 19 with benign PCI, and of these 19, 6 patients had both PCI and PVG. These patients were put under surveillance, and they had no uneventful recovery.

The management of PCI is not well established, there are no standard therapeutic rules. ${ }^{10}$ However, the mandatory in its management is to judge whenever it is benign or life-threatening. ${ }^{11}$ So that it is established that if a CT scan shows intestinal infarction, urgent surgery is mandated. If no signs of intestinal damage is found, a conservative treatment is regarded to be ideal. ${ }^{13}$ The common conservative procedure is to use metronidazole Antibiotics, which affects intestinal bacteria by the suppression of hydrogen production, and hyperbaric oxygen therapy. ${ }^{2,6,8,10}$ Nevertheless, a surgical procedure is indicated in complications such as peritoneal irritation or intestinal obstruction., ${ }^{2,10}$

The second particularity in our case is that the volvulus of the small bowel is due to acute appendicitis. This entity is explained by the wrapping of the appendix, due to its particular length, around the ileum occurring volvulus and strangulation. ${ }^{18,19}$ According to the literature, this mechanism resulted from adhesion of the inflamed appendix to the posterior peritoneum forming a turn of the spire of the ileum last loop resulting in volvulus. ${ }^{18,19}$ In summary, our case is exceedingly rare in the literature, featured by the ileal volvulus due to appendicitis.

\section{Conclusion}

PCI is a rare disease whose diagnosis is offering a challenge for surgeons. This rare condition can often be associated with benign diseases or it can be proof of intestinal necrosis. Although surgery is mandatory in the complicated pattern, the treatment of asymptomatic forms is more likely conservative. Besides, both surgical and medical approaches can efficiently compete with these challenging diagnoses.

\section{Data availability}

All data underlying the results are available as part of the article and no additional source data are required.

\section{Consent}

Written informed consent was obtained from the patient regarding the publication of this case report.

\section{References}

1. Sugihara $\mathrm{Y}, \mathrm{Harada} \mathrm{K}$, Ogawa $\mathrm{H}$, et al.: Pneumatosis Cystoides Intestinalis. 2018; 4

2. Ling F, Guo D, Zhu L: Pneumatosis cystoides intestinalis: a case report and literature review. BMC Gastroenterol. déc 2019; 19(1): 176.

PubMed Abstract | Publisher Full Text | Free Full Text

3. Liau S-S, Cope C, MacFarlane M, et al.: A lethal case of pneumatosis intestinalis complicated by small bowel volvulus. Clin J Gastroenterol. févr 2009; 2(1): 22-26. PubMed Abstract | Publisher Full Text

4. Arora R, El-Hameed AA, Harbi OA: Pneumatosis Intestinalis of Small Bowel in an Adult: A Case Report. Kuwait Med J. 2009; 3. PubMed Abstract | Publisher Full Text

5. Slesser AAP, Patel PH, Das SC, et al.: A rare case of segmental small bowel pneumatosis intestinalis: A case report. Int / Surg Case Rep. 2011; 2(7): 185-187.

PubMed Abstract | Publisher Full Text | Free Full Text

6. Moyon FX, Molina GA, Tufiño JF, et al.: Pneumoperitoneum and Pneumatosis cystoides intestinalis, a dangerous mixture. A case report. Int J Surg Case Rep. 2020; 74: 222-225. PubMed Abstract | Publisher Full Text | Free Full Text

7. Rachid MG, Sadok T, Narjis $Y$, et al.: Occlusive syndrome in intestinal cystic pneumatosis, medical treatment or surgery. PAMJ Clin Med. 2020 [cité 11 janv 2021]; 2. Publisher Full Text | Reference Source

8. Üstüner MA, Dalgıç T, Bostancı EB: Pneumatosis Cystoide Intestinalis: Three Case Reports. Indian J Surg. août 2020; 82(4): 690-692.

Publisher Full Text
9. Fujiya $T$, Iwabuchi $M$, Sugimura $M$, et al.: A Case of Intussusception Associated with Pneumatosis Cystoides Intestinalis. Case Rep Gastroenterol. 12 sept 2016; 10(2): 494-498. Publisher Full Text

10. Di Pietropaolo M, Trinci M, Giangregorio C, et al.: Pneumatosis cystoides intestinalis: case report and review of literature. Clin J Gastroenterol. févr 2020; 13(1): 31-36. PubMed Abstract | Publisher Full Text

11. Rathi C, Pipaliya N, Poddar P, et al.: A Rare Case of Hypermobile Mesentery With Segmental Small Bowel Pneumatosis Cystoides Intestinalis. Intest Res. 2015; 13(4): 346. PubMed Abstract | Publisher Full Text | Free Full Text

12. Wu L-L: A systematic analysis of pneumatosis cystoids intestinalis. World J Gastroenterol. 2013; 19(30): 4973. PubMed Abstract | Publisher Full Text | Free Full Text

13. Brighi M, Vaccari S, Lauro A, et al.: "Cystamatic" Review: Is Surgery Mandatory for Pneumatosis Cystoides Intestinalis? Dig Dis Sci. oct 2019; 64(10): 2769-2775. PubMed Abstract | Publisher Full Text

14. Alves SC, Seidi M, Pires $\mathrm{S}$, et al.: Pneumatosis intestinalis and volvulus: a rare association. 2 .

15. Furihata T, Furihata M, Ishikawa K, et al.: Does massive intraabdominal free gas require surgical intervention? World Gastroenterol. 2016; 22(32): 7383. PubMed Abstract | Publisher Full Text | Free Full Text

16. Wiesner W, Mortelé KJ, Glickman JN, et al.: Pneumatosis Intestinalis and Portomesenteric Venous Gas in Intestinal Ischemia: Correlation of CT Findings with Severity of Ischemia and Clinical Outcome. Am J Roentgenol. déc 2001; 177(6): 
1319-1323.

PubMed Abstract | Publisher Full Text

17. Sooby P, Harshen R, Joarder R: An unusual triad of pneumatosis intestinalis, portal venous gas and pneumoperitoneum in an asymptomatic patient. J Surg Case Rep. 8 avr 2015; 2015(4): rjv035-rjv035.

PubMed Abstract | Publisher Full Text | Free Full Text

18. Harrison S, Mahawar K, Brown D, et al.: Acute appendicitis presenting as small bowel obstruction: two case reports. Cases J. déc 2009; 2(1): 9106.

PubMed Abstract | Publisher Full Text | Free Full Text

19. Assenza M, Ricci G, Bartolucci P, et al.: Mechanical small bowel obstruction due to an inflamed appendix wrapping around the last loop of ileum. 6 . PubMed Abstract

20. Rodríguez González M, de los Á Mejías Manzano M, Sobrino López AM, et al.: Primary or idiopathic intestinal pneumatosis: a rare casual endoscopic finding. Rev Esp Enfermedades Dig. 2021 [cité 6 juin 2021].

Reference Source

21. Takahashi K, Fujiya M, Ueno N, et al.: Endoscopic Fine-Needle Aspiration Is Useful for the Treatment of Pneumatosis Cystoides Intestinalis With Intussusception. Am J Gastroenterol. janv 2019; 114(1): 13-13.

PubMed Abstract | Publisher Full Text

22. Suda T, Shirota $Y$, Wakabayashi T: Pneumatosis Cystoides Intestinalis. Clin Gastroenterol Hepatol. mars 2019; 17(4): A33-A34. PubMed Abstract | Publisher Full Text | Free Full Text

23. Lin W-C, Wang K-C: Pneumatosis Cystoides Intestinalis Secondary to Use of an a-Glucosidase Inhibitor. Radiology. mars 2019; 290(3): 619-619.

PubMed Abstract | Publisher Full Text

24. Romano-Munive AF, Barreto-Zuñiga R: Pneumatosis cystoides intestinalis. 1.

PubMed Abstract | Publisher Full Text | Free Full Text

25. Fraga M, da Silva MJN, Lucas M: Idiopathic Pneumatosis Intestinalis, Radiological and Endoscopic Images. GE Port J Gastroenterol. sept 2016; 23(5): 270-2.

PubMed Abstract | Publisher Full Text | Free Full Text

26. Tseng $\mathrm{P}-\mathrm{Y}$, Tarng $\mathrm{D}-\mathrm{C}$, Yang $\mathrm{W}-\mathrm{C}$, et al.: Benign Pneumatosis Intestinalis. Intern Med. 2014; 53(14): 1589-1590. PubMed Abstract | Free Full Text

27. Nagata S, Ueda N, Yoshida Y, et al.: Pneumatosis coli complicated with intussusception in an adult: Report of a case. Surg Today. mai 2010; 40(5): 460-464.

PubMed Abstract | Publisher Full Text 


\section{Open Peer Review}

\section{Current Peer Review Status: ? ? ?}

\section{Version 1}

Reviewer Report 20 October 2021

https://doi.org/10.5256/f1000research.76663.r94999

(C) 2021 Mesina C. This is an open access peer review report distributed under the terms of the Creative Commons Attribution License, which permits unrestricted use, distribution, and reproduction in any medium, provided the original work is properly cited.

\section{Cristian Mesina}

Department of Surgery, Craiova University of Medicine and Pharmacy, Craiova, Romania

1. During the clinical examination of the abdomen it would have been better to explain what was found on the percussion of the abdomen.

2. Digital rectal examination was to be included in the clinical examination of the patient.

3. Biological paraclinical examinations should have been more extensive to highlight whether or not there existed the presence of toxic-septic shock.

4. The intraoperative exploration of the peritoneal cavity, the cause of pneumoperitoneum, should have been better explained.

Is the background of the case's history and progression described in sufficient detail? Yes

Are enough details provided of any physical examination and diagnostic tests, treatment given and outcomes?

Partly

Is sufficient discussion included of the importance of the findings and their relevance to future understanding of disease processes, diagnosis or treatment?

Yes

Is the case presented with sufficient detail to be useful for other practitioners? Yes

Competing Interests: No competing interests were disclosed.

Reviewer Expertise: surgery 


\section{I confirm that I have read this submission and believe that I have an appropriate level of expertise to confirm that it is of an acceptable scientific standard, however I have significant reservations, as outlined above.}

Author Response 07 Dec 2021

meryam meryam, Habib thameur Hospital, Tunis, Tunisia

Dear Sir,

I appreciate the time and effort that you and the reviewers have dedicated to providing your valuable feedback on my manuscript. I am grateful to the reviewers for their insightful comments on our paper. I have been able to incorporate changes to reflect most of the suggestions provided by the reviewers.

Thank you, sincerely.

Competing Interests: No competing interests were disclosed.

Reviewer Report 13 October 2021

https://doi.org/10.5256/f1000research.76663.r94998

(c) 2021 Waisberg J. This is an open access peer review report distributed under the terms of the Creative Commons Attribution License, which permits unrestricted use, distribution, and reproduction in any medium, provided the original work is properly cited.

\section{Jaques Waisberg}

Department of Surgery, Institute of Medical Assistance to State Civil Servants (IAMSPE), Sao Paulo, Brazil

\section{General considerations:}

The clinical relevance of pneumatosis intestinalis varies widely from benign to potentially fatal conditions, depending on the underlying cause of pneumatosis intestinalis, which can lead to high mortality if surgery is delayed when necessary. Mesenteric ischemia, intestinal obstruction, and intestinal necrosis represent the fatal causes of pneumatosis intestinalis. It is challenging to distinguish between those patients who require surgery and those who can be observed or treated conservatively with adequate treatment of the underlying disease. The diagnosis of intestinal pneumatosis is made by computed tomography or plain abdominal radiography. Computed tomography is the most sensitive imaging modality. A strong indicator of the presence of mesenteric infarction or ischemia is the association of pneumatosis intestinalis with gas in the portal venous blood.

Surgery is not indicated in asymptomatic patients with radiographic signs of pneumatosis intestinalis but no signs of bowel obstruction or free peritoneal air. Intestinal ischemia is the most 
likely cause, and a delay in surgery will worsen the patient's condition. When non-surgical treatment is initially performed, the patient must be re-evaluated later. Surgery must be performed if there is no response to conservative treatment or if the patient's condition worsens.

This is an exciting manuscript about a rare case of pneumatosis intestinalis in an adult patient. The subject covered by the manuscript is required for clinical practice. This manuscript has scientific value due to the rarity of the case. However, this case report needs some adjustments.

Specific considerations:

Title - Appendix necrosis is identified as one of the contributing causes for the onset of pneumatosis intestinalis. As the authors themselves state in the text, appendicitis was the determining factor for small bowel volvulus. The title should include this information. The authors perform a literature review (Table 1 and 27 references), so the term "literature review" needs to be in the title.

Abstract - The conclusion that "This case report emphasizes the importance of surgical procedures in the management of symptomatic pneumatosis intestinalis" needs to be contextualized according to the underlying disease, as this is precisely the dilemma that is faced with distinguishing the clinical or surgical approach in symptomatic cases of pneumatosis intestinalis.

Discussion - The terms "primary" and "idiopathic" pneumatosis intestinalis are equivalent, so I suggest unifying them. A thorough explanation of the theories of the pathogenesis of intestinal pneumatosis is not necessary for the case description. I also recommend not using the term "benign PCI," just "PCI". Is there a "malignant PCI"? What were the reasons for six patients with "benign" PCI and PVG "not having" or "having" an uneventful recovery? Please remove the term "Antibiotics" after the word "metronidazole".

Figures - The legends of figures 1 to 5 are incomplete, as they must be self-explanatory (Exam name, disease name). Highlights in the legend must be marked with arrows on the figure itself. In figures with arrows, the pointed structure must be indicated in the legend. Figures 6 and 7 are unnecessary, as they do not add relevant information to the report.

Is the background of the case's history and progression described in sufficient detail? Yes

Are enough details provided of any physical examination and diagnostic tests, treatment given and outcomes?

Yes

Is sufficient discussion included of the importance of the findings and their relevance to future understanding of disease processes, diagnosis or treatment?

No

Is the case presented with sufficient detail to be useful for other practitioners?

No 
Competing Interests: No competing interests were disclosed.

Reviewer Expertise: Gastrointestinal Surgery

I confirm that I have read this submission and believe that I have an appropriate level of expertise to confirm that it is of an acceptable scientific standard, however I have significant reservations, as outlined above.

Author Response 07 Dec 2021

meryam meryam, Habib thameur Hospital, Tunis, Tunisia

Dear Sir,

I appreciate the time and effort that you and the reviewers have dedicated to providing your valuable feedback on my manuscript. I am grateful to the reviewers for their insightful comments on our paper. I have been able to incorporate changes to reflect most of the suggestions provided by the reviewers.

Thank you, sincerely.

Competing Interests: No competing interests were disclosed.

Author Response 16 Oct 2022

meryam meryam, Habib thameur Hospital, Tunis, Tunisia

thank you for your efforts i made all the corrections

Competing Interests: No competing interests were disclosed.

Reviewer Report 12 October 2021

\section{https://doi.org/10.5256/f1000research.76663.r95001}

(c) 2021 Martines G. This is an open access peer review report distributed under the terms of the Creative Commons Attribution License, which permits unrestricted use, distribution, and reproduction in any medium, provided the original work is properly cited.

\section{Gennaro Martines}

Department of Emergency and Organ Transplantation, University "Aldo Moro" of Bari, Bari, Italy

'Pneumatosis intestinalis (PI), described by Du Vernoy in 1730, is a rare condition that refers to the presence of multiple gaseous cysts in the intestinal submucosa and subserosa with a reported incidence of $0.03 \%$. It can be divided between a benign form and in a life-threatening condition requiring surgery. 
The radiographic incidence of PI has been reported to be up to $0.37 \%$ of patients who have abdominal computed tomography (CT) scans. PI can be divided into the primary/idiopathic type (15\%), which refers to air pockets that imply to a chronic and benign idiopathic etiology, and the secondary type (85\%), which refers to radiological findings of linear, microvesicular, or more circumferential appearing intramural gas caused by several predisposing factors. The peak age at onset is $45.3 \pm 15.6$ years with a male to female ratio of $2.4: 1 .^{1}$

This is an interesting paper which describes an unusual case of pneumatosis intestinalis. This situation is associated with many causes of bowel obstruction, and often requires a surgical approach in an emergency.

The manuscript is well described but I want to ask why the authors perform a laparoscopy. In these situations there is a distension of the bowel which does can make this kind of approach risky. Can they explain this decision as a surgical approach?

All the other parts are well described with adequate diagnostic steps.

\section{References}

1. Dibra R, Picciariello A, Trigiante G, Labellarte G, et al.: Pneumatosis Intestinalis and Hepatic Portal Venous Gas: Watch and Wait or Emergency Surgery? A Case Report and Literature Review. Am J Case Rep. 2020; 21: e923831 PubMed Abstract | Publisher Full Text

Is the background of the case's history and progression described in sufficient detail? Yes

Are enough details provided of any physical examination and diagnostic tests, treatment given and outcomes?

Yes

Is sufficient discussion included of the importance of the findings and their relevance to future understanding of disease processes, diagnosis or treatment?

Yes

Is the case presented with sufficient detail to be useful for other practitioners? Yes

Competing Interests: No competing interests were disclosed.

Reviewer Expertise: general surgery

I confirm that I have read this submission and believe that I have an appropriate level of expertise to confirm that it is of an acceptable scientific standard, however I have significant reservations, as outlined above. 
meryam meryam, Habib thameur Hospital, Tunis, Tunisia

Dear Sir,

I appreciate the time and effort that you and the reviewers have dedicated to providing your valuable feedback on my manuscript. I am grateful to the reviewers for their insightful comments on our paper. I have been able to incorporate changes to reflect most of the suggestions provided by the reviewers.

Thank you, sincerely.

Competing Interests: No competing interests were disclosed.

Author Response 16 Oct 2022

meryam meryam, Habib thameur Hospital, Tunis, Tunisia

the first laparoscopic pathway was indicated in the first place as an easy and minimally invasive exploratory approach.

Competing Interests: No competing interests were disclosed.

The benefits of publishing with F1000Research:

- Your article is published within days, with no editorial bias

- You can publish traditional articles, null/negative results, case reports, data notes and more

- The peer review process is transparent and collaborative

- Your article is indexed in PubMed after passing peer review

- Dedicated customer support at every stage

For pre-submission enquiries, contact research@f1000.com 